\title{
Performance Comparison of Two Airfoil Rotor Designs for an Agricultural Unmanned Helicopter
}

\author{
Young Mo Koo* \\ Dept. of Bio-industrial Engineering, Kyungpook National University, Daegu, Korea \\ Received: February $13^{\text {th }}, 2012$; Revised: February $20^{\text {th }}, 2012$; Accepted: February $24^{\text {th }}, 2012$
}

\section{Abstract}

Purpose: The most important element of an agricultural helicopter is the rotor blade realizing lift force. In order to improve the performance of the rotor blades, two types (KA152313 and KB203611) of airfoils were designed and compared. Methods: The nose shape of the KB203611 airfoil was 'drooped' and 'sharp' compared to the leading edge of the KA152313 airfoil. The performance of the experimental airfoils was simulated using CFD-ACE program, and lifts were measured in situ using the 'AgroHeli-4G', a prototype helicopter. Results: Simulated lifts of the blade with the KA152313 airfoil showed proper values for a wide range of angles of attack between $14^{\circ} \sim 18^{\circ}$, while the simulated lift of the KB203611 blade exhibited maximum values near $13^{\circ} \sim 14^{\circ}$. In the lift measurements, the range of operable angles of attack was a collective pitch angle at the grip (GP) of $12^{\circ} \sim 18^{\circ}$ for the KA152313 blade. On the other hand, the range of angles of attack for the KB203611 blade was a GP of $12^{\circ} \sim 14^{\circ}$. Conclusions: The blade of KA152313 performed well over a wide range of AoAs and the blade of KB203611 performed better at low AoAs. In this study, a variative airfoil blade, gradually emerging from grip to tip using the two different airfoils, was suggested.

Keywords: Agricultural unmanned helicopter, Airfoil, CFD simulation, Drag, Lift, Rotor blade

\section{Introduction}

Problems such as lack of workers and decreasing population in the agricultural sector of Korea have been overcome mostly by the mechanization of the farming operations. Among them, chemical spraying has been seriously considered as an irritating and annoying job for Korean rice growers. An agricultural unmanned helicopter was suggested to solve these problems so that farmers could have better farming conditions. Aerial application of chemicals with an agricultural helicopter allows for precise and timely spraying and reduces the labor and environmental pollution involved in the farming process. Concerned with sustainable agriculture, spray coverage may increase but the drift of the fumes decrease, with the advantage of deep penetration by the rotor down-wash

\footnotetext{
*Comesponding author: Young Mo Koo

Tel: +82-53-950-5788; Fax: +82-53-950-6780

E-mail: ymkoo@knu.ac.kr
}

(Koo et al., 2006a).

Aerial application using an unmanned helicopter was successfully adapted for small scale farming of land with ultra-low application rates. Unmanned aerial spraying technology is an efficient and practical tool to achieve stable agricultural production to improve the working environment, and to reduce the work load of the operators (Koo et al., 2006b).

For design of a helicopter rotor, one may select one of the many airfoils that have been already investigated or design an entirely new airfoil to incorporate desirable characteristics. The desirable characteristics of a good airfoil for a helicopter rotor are as follows (Prouty, 2002):

1) High maximum static and dynamic lift coefficients to allow flight with high maneuver load factors.

2) High drag divergence Mach number to allow flight without prohibitive power losses or noise.

3) Low drag at moderate lift coefficients to minimize the power in normal flight conditions. 
4) Low pitching moment to minimize blade torsional moments.

5) An aft aerodynamic center position to minimize the nose ballast required to balance the blade.

Unfortunately, because many of these requirements conflict with each other, the choice for the best airfoil is not an easy task. However, one or more of the airfoil performance can be maximized without drastically compromising another. To do this, requires an understanding of the major interrelated effects of factors such as airfoil shape, the angle of attack (AoA), Reynolds Number (Re), and Mach Number (Mach) for the aerodynamic performance.

There have been studies on the CFD simulation of experimental airfoils and analysis of rotor performance to compare the simulation results with the experimental test results (Park et al., 2004; Sa et al. 2010). Thus, the optimal models for rotors can be adapted for an unmanned small-scaled agricultural helicopter. The selection of airfoil sections for helicopter rotors is more difficult than for a fixed-wing aircraft because they are not consistent point designs that is, AoA and Mach vary continuously along the blade span and one type of airfoil section cannot meet all the various aerodynamic requirements (Leishman, 2002).

Sa et al. (2010) designed an optimal rotor consisted of three different airfoils along the rotor span using the $k-\omega$ Wilcox-Durbin turbulence model. The section of the airfoil gradually thinned toward the tip from a thickness ratio of $12 \%$ to $7 \%$. The design criteria were a high lift at the inner section and a high drag divergence Mach number at the outer section. As a result of simulation, the drag coefficient was reduced and the rotor performance was improved.

Kim (2005) conducted aerodynamic analyses for ten helicopter rotor airfoils to generate a preliminary design using the Spalart-Allmaras turbulence model of FLUENT. The aerodynamic coefficients of lift, drag and pitching moment were determined and compared with respect to the shape of the airfoil. The thickness ratio, reflex camber, attack angle, Re and Mach affected the coefficients and the location of the pressure center.

The agricultural helicopter for aerial application maneuvers is relatively slow at $15-25 \mathrm{~km} / \mathrm{h}$ (about 10 knots); therefore, the aerodynamic characteristics could be assumed as nearly hovering (Koo et al., 2006b). The airfoils used for small-scale agricultural helicopters are operated at low $\operatorname{Re}\left(1.0310^{6}\right)$ and Mach (0.4). Therefore, flow sep- aration on the airfoil would occur at a low AoA because of the weak flow momentum. Furthermore, it is expected that the drag rapidly increases and the maximum lift coefficient decreases. Park et al. (2004) designed an improved airfoil for the low Re operations according to two design objectives: the maximum figure of merit and the minimum coefficient of drag using the Spalart-Allmaras turbulence model.

The objective of this study was to improve the performance of rotor blades for an agricultural helicopter. Two types of airfoils were designed and compared using the CFD simulation method and experimental lift tests. The lift characteristic was fluid-mechanically analyzed and compared with respect to the airfoil design.

\section{Materials and Methods}

\section{Shapes of the experimental airfoils}

Figure 1 shows the experimental airfoils, KA152313 and KB203611, used in the design study. The airfoils were designated according to the NACA (National Advisory Committee for Aeronautics) system. The designation system presented as AAnnppxx consisted of four notations: the first two letters followed by three 2-digits notations. The first two letters refer to the K-series, and then the next three notations are the permil of the maximum camber, the percent position of maximum camber, and

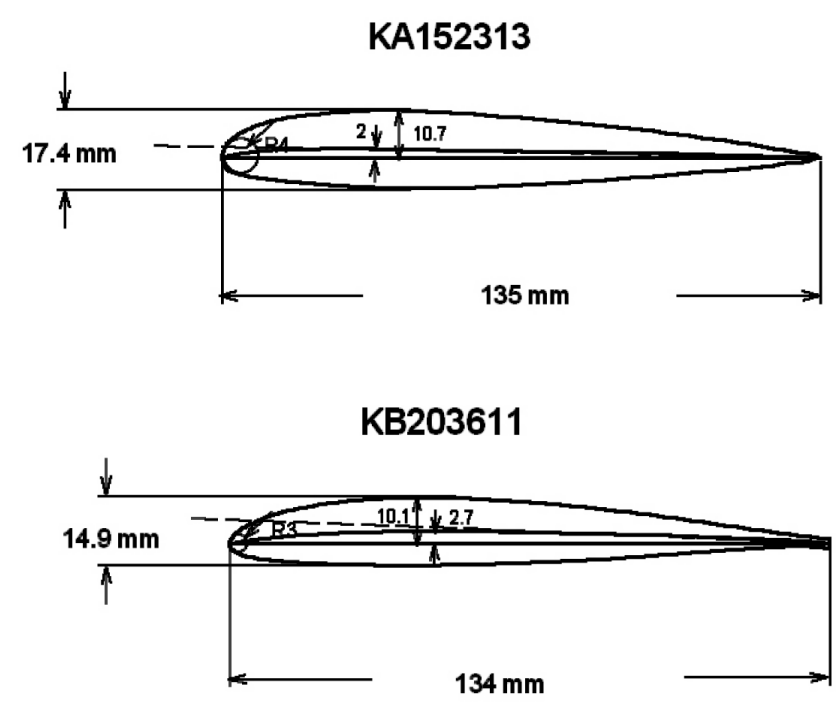

Figure 1. Experimental airfoils designed for the agricultural helicopter rotor. 


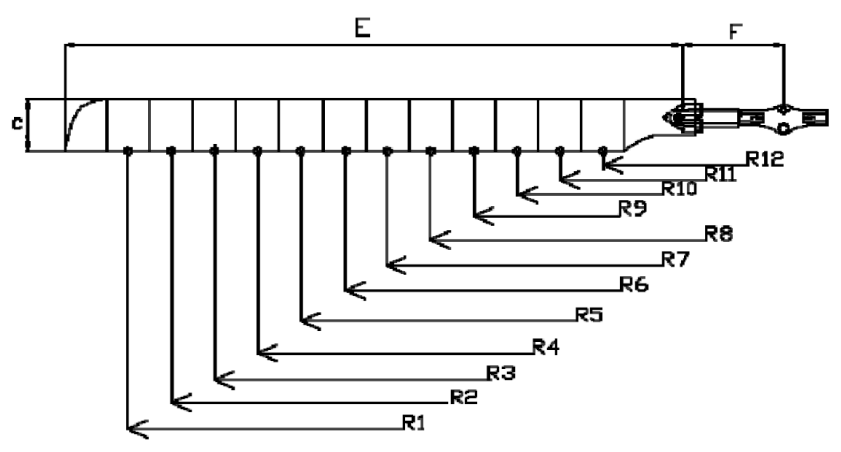

Figure 2. Dimensions and definition of the radius rotor sections for CFD simulation.

the percent of maximum thickness to the chord length, respectively.

The two airfoils had a similar chord length (c) (Figure 2), but the KB203611 airfoil was thinner than KA152313. The camber for the KB203611 airfoil was greater than that of KA152313, so that the nose of the KB203611 airfoil became drooped (Table 1). The nose radius of the KA152313 at the leading edge was greater; that is, the airfoil had a sharp nose compared to the blunt nose of the KA152313 airfoil. The maximum camber for the KB203611 airfoil was located at $35.8 \%$ aft chord, compared to $22.7 \%$ for the KA152313 airfoil.

\section{CFD simulation and rotor system}

The performance of the experimental airfoils was simulated to determine the distributions of the pressure force, shear force and pitching moment on the chord surface using CFD-ACE program, as discussed in a previous study
(Seok et al., 2006b). An unstructured triangular mesh was applied for better resolution of the simulation results for the vortex area. Using the Spalart-Allmaras turbulence model, the aerodynamic coefficients of normal (lift), axial (drag), and pitching moment $\left(\mathrm{C}_{\mathrm{N}}, \mathrm{C}_{\mathrm{A}}\right.$ and $\mathrm{C}_{\mathrm{m} 1 / 4}$, respectively) in the 2-D flow field were determined and compared.

The simulations were conducted for the radii along the blade span, shown in Figure 2. The rotor span was divided into 12 sections $(10 \mathrm{~cm}$ each) for diametral simulation, and details of the simulation data were tabulated in Table 2. The total lengths (E) of blades to the tip from pin for the two blades were similar; however, the distances from the center of the master shaft to the pin (F) were 157 and 190 mm for the blades of KB203611 and KA152313 airfoils, respectively. Thus, the tip radii of the blades with KB203611 and KA152313 airfoils were 1507 and $1570 \mathrm{~mm}$, respectively. The blades with KB203611 and KA152313 airfoils were twisted toward the inner section with wash-out angles of $6^{\circ}$ and $4^{\circ}$. The AoA was designated with the collective pitch angle at the grip (GP). In Table 2 , the AoA for each section is presented under a nominal GP of $12^{\circ}$. The experimental rotors of KB203611 and KA152313 airfoils are shown in Figure 3 (a) and (b), respectively.

\section{Force and moment coordinates}

The simulation returns the normal pressure force $(p)$ and axial shear force $(\tau)$ per unit span (meter) at the nodes chord-wise ( $x-y$ coordinate) along the upper and lower surfaces. The corresponding coefficients of the pressure force, $C_{p}$ and shear force, $C_{s}$ are defined in Eq. (1):

Table 1. Dimensions of the experimental airfoils $(\mathrm{mm})$

\begin{tabular}{ccccccc}
$\begin{array}{c}\text { Airfoil } \\
\text { Name }\end{array}$ & $\begin{array}{c}\text { Chord } \\
\text { length }(\mathrm{c})\end{array}$ & $\begin{array}{c}\text { Max. } \\
\text { thickness }\end{array}$ & $\begin{array}{c}\text { Max upper } \\
\text { camber }\end{array}$ & $\begin{array}{c}\text { Point of } \\
\text { max camber }\end{array}$ & $\begin{array}{c}\text { Camber } \\
\text { Leading edge } \\
\text { radius }\end{array}$ \\
\hline KA152313 & 135 & 17.4 & 10.7 & 30.7 & 2 & 4 \\
KB203611 & 134 & 14.9 & 10.1 & 48.0 & 2.7 & 3 \\
\hline
\end{tabular}

Table 2. Rotor radii and pitch angles of attack (AoA) for the sections of the experimental rotors at a nominal GP of $12^{\circ}$

\begin{tabular}{|c|c|c|c|c|c|c|c|c|c|c|c|c|c|c|c|c|c|}
\hline \multirow{2}{*}{$\begin{array}{l}\text { Airfoil } \\
\text { name }\end{array}$} & \multirow{2}{*}{$\begin{array}{c}\text { Length } \\
\text { pin to } \\
\text { tip (E) } \\
(\mathrm{mm})\end{array}$} & \multirow{2}{*}{$\begin{array}{l}\text { Distance } \\
\text { pin to } \\
\text { Center (F) } \\
(\mathrm{mm})\end{array}$} & \multirow{2}{*}{$\begin{array}{c}\text { AoA } \\
\& \\
\text { Radius }\end{array}$} & \multicolumn{14}{|c|}{ Rotor section No. } \\
\hline & & & & Grip & $\mathrm{R} 12$ & R11 & R10 & R9 & R8 & $\mathrm{R} 7$ & $\mathrm{R} 6$ & R5 & R4 & R3 & $\mathrm{R} 2$ & $\mathrm{R} 1$ & Tip \\
\hline \multirow{2}{*}{$\begin{array}{c}\text { KA } \\
152313\end{array}$} & \multirow{2}{*}{1350} & \multirow{2}{*}{157} & $\mathrm{AoA}\left({ }^{\circ}\right) @ \mathrm{GP} 12$ & 12 & 12 & 11.5 & 11 & 10.5 & 10 & 9.5 & 9 & 8.5 & 8 & 7.5 & 7 & 6.5 & 6 \\
\hline & & & Radius (mm) & 157 & 297 & 397 & 497 & 597 & 697 & 797 & 897 & 997 & 1097 & 1197 & 1297 & 1397 & 1507 \\
\hline \multirow{2}{*}{$\begin{array}{c}\mathrm{KB} \\
203611\end{array}$} & \multirow{2}{*}{1380} & \multirow{2}{*}{190} & $\operatorname{AoA}\left({ }^{\circ}\right) @ \mathrm{GP} 12$ & 12 & 12 & 12 & 12 & 12 & 12 & 12 & 11.4 & 10.8 & 10.2 & 9.7 & 9.1 & 8.5 & 8 \\
\hline & & & Radius (mm) & 190 & 342 & 442 & 542 & 642 & 742 & 842 & 942 & 1042 & 1142 & 1242 & 1342 & 1442 & 1570 \\
\hline
\end{tabular}




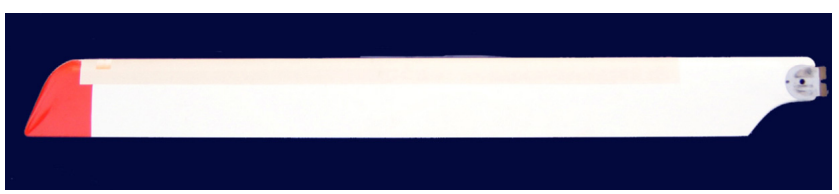

(a) KA152313 airfoil

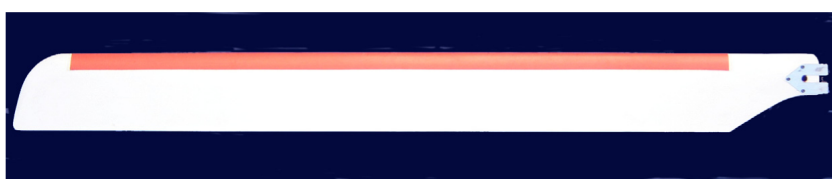

(b) KB203611 airfoil

Figure 3. Rotor designs of two different airfoils used in the comparative experiment.

$$
C_{p}=\frac{p-p_{\infty}}{q_{\infty}}, C_{s}=\frac{\tau}{q_{\infty}}
$$

where, $p_{\infty}$ : the atmospheric pressure, and

$$
q_{\infty}=\frac{1}{2} \rho_{\infty} V_{\infty}^{2} \text {, the kinetic energy. }
$$

Eq. (2) summates the $p$ and $\tau$ per unit span at the nodes into the normal force $(\mathrm{N})$ and axial force $(\mathrm{A})$ for each local span of the section $(10 \mathrm{~cm})$.

$$
\begin{aligned}
& N=\oint(-p \cos \alpha+\tau \sin \alpha) d A, \\
& A=\oint(-p \sin \alpha+\tau \cos \alpha) d A
\end{aligned}
$$

The lift (L) and drag (D) in the earth coordinate (X-Y reference) were obtained by resolving $\mathrm{N}$ and $\mathrm{A}$ in a chord-wise local coordinate $(x-y)$ through the AoA $(\alpha)$ from the resultant (R) in Figure 4. The simulation results were calculated to the lift (L) and drag (D) in the earth coordinate, and the pitching moment at 1/4-chord $\left(\mathrm{M}_{1 / 4}\right)$ using Eqs (3) and (4). The center of moment $\left(x_{c p}\right)$ can be also estimated using Eq. (5).

$$
\begin{aligned}
& L=N \cos \alpha+A \sin \alpha, D=N \sin \alpha-A \cos \alpha \\
& M_{1 / 4}=N(x-c / 4)
\end{aligned}
$$

where, $\mathrm{M}_{1 / 4}$ is the pitching moment at 1/4-chord.

$$
x_{c p}=\frac{1}{4}-\frac{M_{1 / 4}}{N}
$$

The corresponding force and moment coefficients are defined in Eq. (6) as follows:

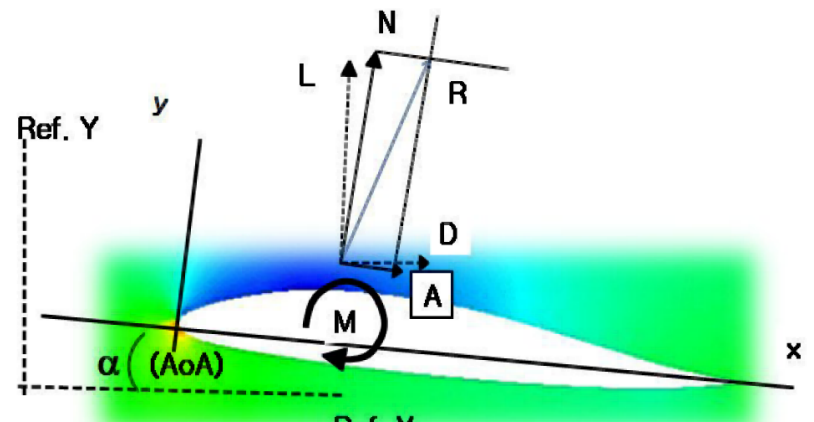

Ref. X

Figure 4. Force coordinates system on the airfoil. (x-y: local coordinates; Ref. X-Y: earth coordinates)

$$
C_{N}=\frac{N}{q_{\infty} c}, \quad C_{A}=\frac{A}{q_{\infty} c}, \quad C_{m 1 / 4}=\frac{M_{1 / 4}}{q_{\infty} c^{2}}
$$

where, $C_{N}, C_{A}$, and $C_{m 1 / 4}$ are the coefficients of the normal force, axial force and moment at 1/4-chord, additionally, $\mathrm{c}$ is the chord length.

As mentioned above, a good rotor with modified airfoils for a small scaled helicopter could be evaluated by understanding the interaction of the following factors: 1) relaxed distribution of $\mathrm{Cp}$ and $\mathrm{Cs}, 2$ ) maximal $\mathrm{C}_{\mathrm{N}}$ and minimal $\mathrm{C}_{\mathrm{A}}$, 3 ) the tendencies of $L$ and $D$ with respect to AoA, 4) high $\mathrm{L}$ and low $\mathrm{D}, 5$ ) high $\mathrm{C}_{\mathrm{N}}$ at the inner span, and low $\mathrm{C}_{\mathrm{A}}$ at the outer span, 6) ranges for $\mathrm{Re}$ and Mach, 7) applicable range of AoA, 8) aft location of $x_{c p}$, the moment center, and 9) low pitching moment. The performance and characteristics of the rotors can be improved through the airfoil by modifying the thickness and camber ratios, drooping or sharpness of the nose design, and the reflex or tab.

\section{Experimental measurement of lift}

The agricultural helicopter used in the lift measurement in situ was the 'AgroHeli-4G', a prototype helicopter designed and constructed by Kyungpook National University (Koo et al., 2009). The capacity of the total lift is up to $1078 \mathrm{~N}$ (110 kg $)$ with an engine power of $23.5 \mathrm{~kW}$ (32 PS).

As reported by Koo et al. (2006b, 2010), the helicopter was setup on the load-cell system (L2350/L2, Futek, Irvine, CA, USA), which can measure the payload over a deadweight $(640 \mathrm{~N})$ while maintaining a trim condition as shown in Figure 5(a). The helicopter and load-cell system was anchored on a platform and guided with two linear bearing columns.

For the sake of convenience, an LED display (L20010WM1, 


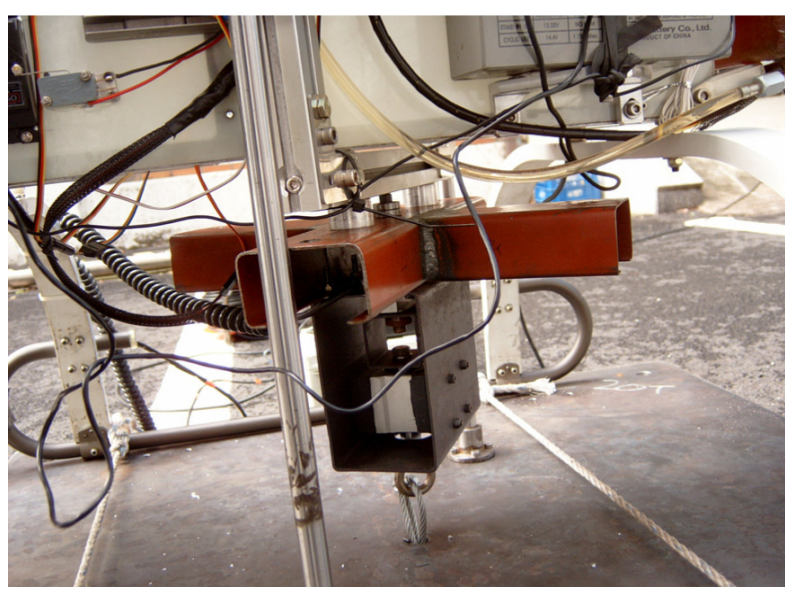

(a) load-cell system

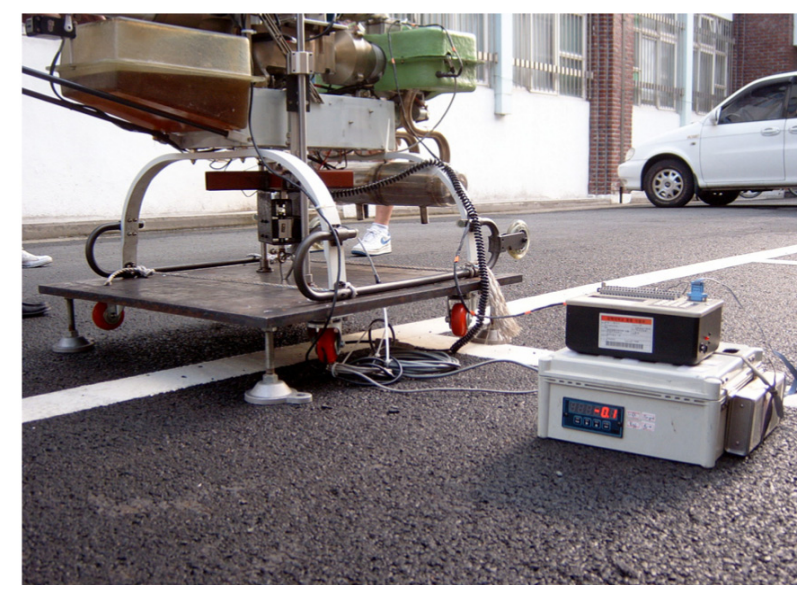

(b) display and data logger

Figure 5. Lift measurement apparatus using a load cell system and display.
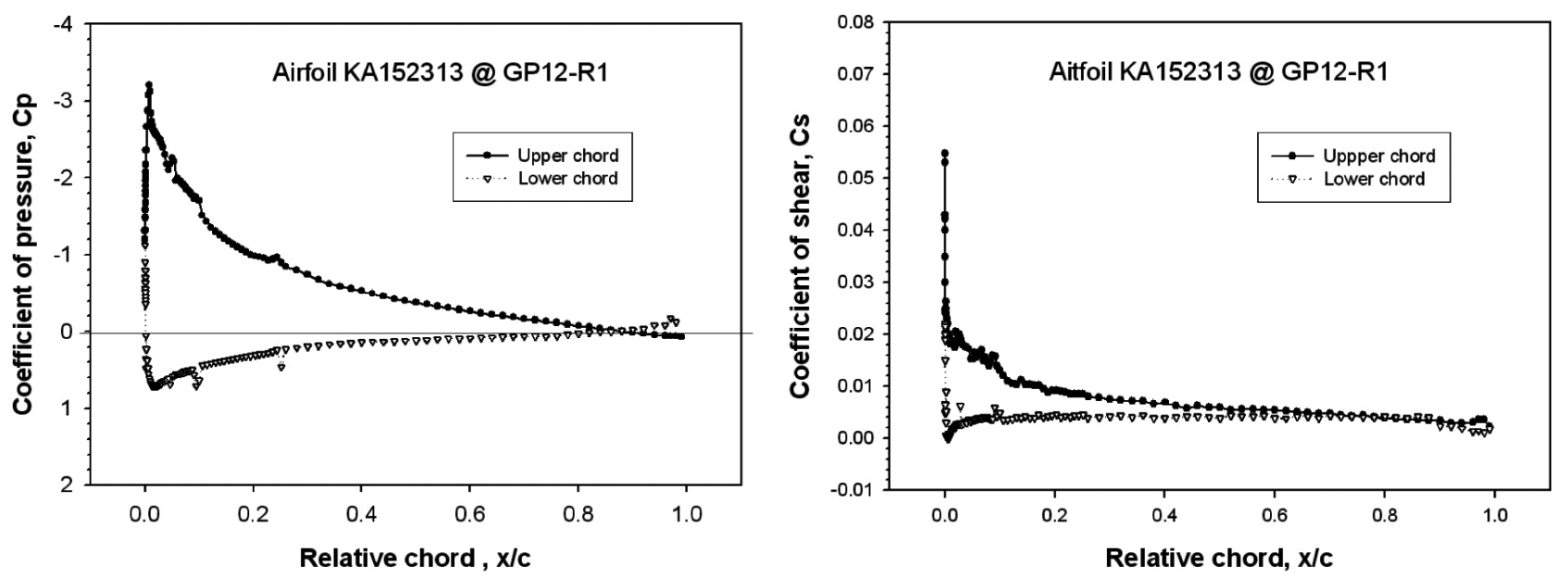

Figure 6. Distributions of the $\mathrm{Cp}$ and $\mathrm{Cs}$ on the chords of KA152313 airfoil at a grip pitch of $12^{\circ}$.

Laurel Elec. Inc., Costa Mesa, CA, USA) indicating the lift of payload was prepared and the lifts were acquired with a data logger (21X-SM192, Campbell Scientific Inc., Logan, UT, USA) as shown in Figure 5(b).

To measure lifts at various grip pitches, the collective pitch console was calibrated to the pitch angle, coupled with the engine speed. An experimental rotor for KA152313 airfoil was tested for GPs of $12,13,14,16$, and $18^{\circ}$. The other experimental rotor for KB203611 airfoil was tested at the GPs of $10,12,13$, and $14^{\circ}$.

\section{Results and Discussion}

\section{Pressure and turbulence patterns on the airfoils}

Figures 6 and 7 compared the distributions of the pressure and shear forces along the upper and lower chords of the experimental airfoils at the rotor section R1 for a nominal GP of $12^{\circ}$. The pressure and shear forces were presented with the coefficients of pressure and shear, defined in Eq. (1), using the local linear velocity of the rotor section.

The pressure coefficient on the upper chord remained suction and positive on the lower chord. The clear difference between the two distributions was the shapes of the pressure and shear changes near nose. The closed area between the chords showed lift per unit length of the span. The area of KB203611 airfoil was greater than that of KA152313. The stiff change of KA152313 contrasted with the relaxed one of KB203611 airfoil.

The nose shape of KB203611 airfoil was 'drooped' and 'sharp' compared to the leading edge of KA152313 airfoil. This drooped and sharp nose modifies the path from the 

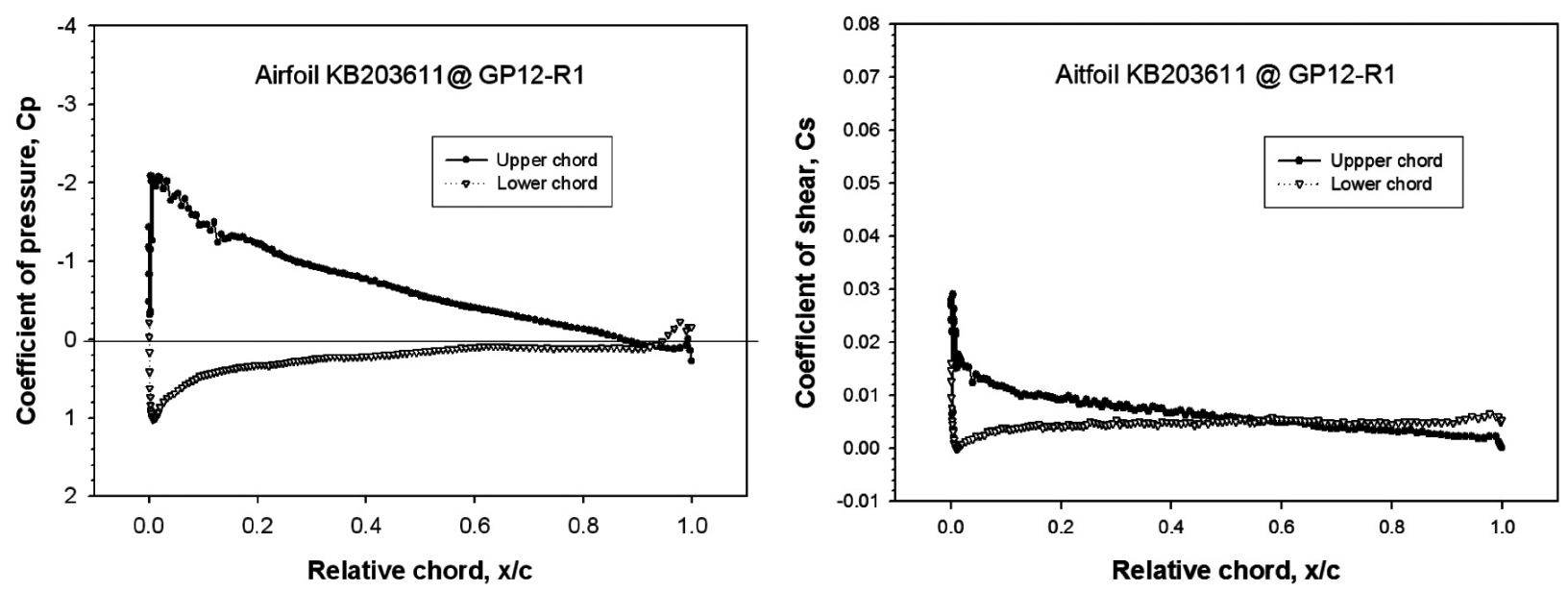

Figure 7. Distributions of the $\mathrm{Cp}$ and $\mathrm{Cs}$ on the chords of KB203611 airfoil at a grip pitch of $12^{\circ}$.

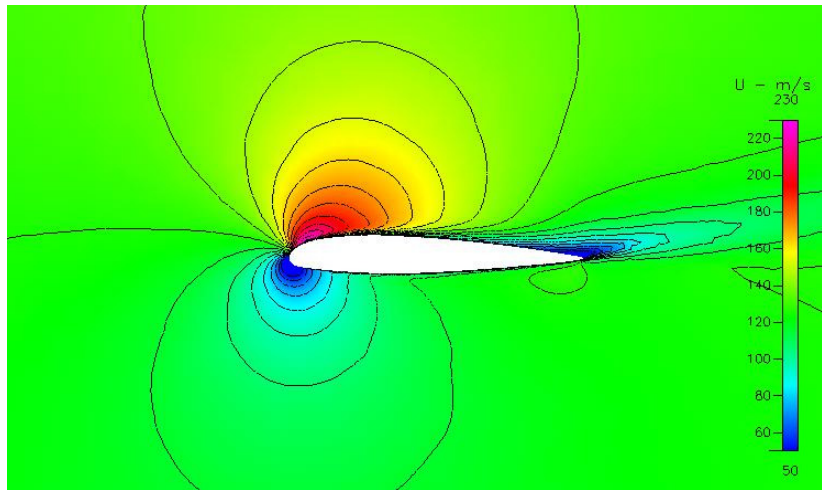

(a) KA152313

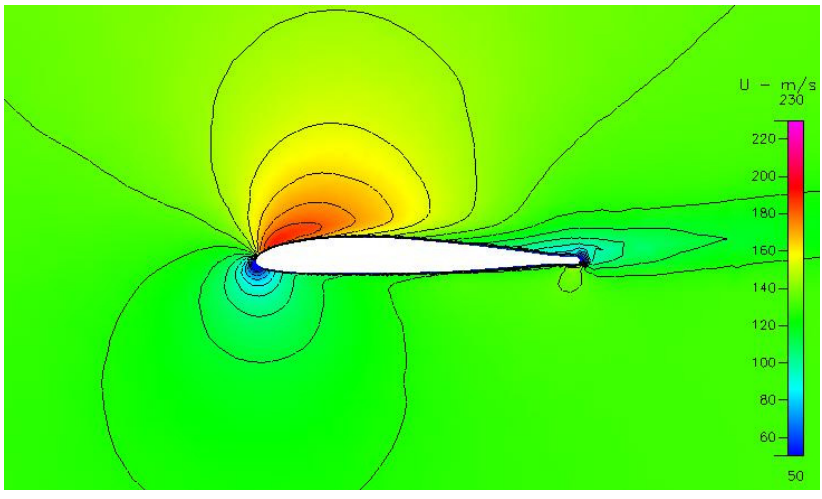

(b) KB203611

Figure 8. Flow velocity $(\mathrm{U})$ contours near airfoils at a grip pitch of $12^{\circ}$.

stagnation point to the upper surface. Because of the less violent changes in the curvature and direction experienced as the molecules travel over the nose, the local velocities are reduced. This may decrease the centrifugal force on the air, delaying the formation of the laminar separation bubble and also decreasing the magnitude of the deceleration required as the flow goes toward the trailing edge, thus decreasing the unfavorable pressure gradient (Prouty, 2002).

The maximum static lift that can be developed by an airfoil was found to be related to the type of stall characteristic of the airfoil. The KA152313 airfoil was thicker with a blunt nose and greater thickness ratio than those of KB203611. Increasing the thickness and roughening nose causes the trailing edge stall. For those airfoils that stall at the trailing edge, the maximum lift coefficient was nearly constant as the AoA changed.

The trailing edge stall is caused by the gradual separation of the turbulent boundary layer, starting at the trailing edge and expanding forward. Thickening the boundary layer through surface roughness produces early stall and thus reduces the maximum lift coefficient. Trailing edge stall is gradual in both lift and moment and has no hysteresis (Prouty, 2002).

On the other hand, the drooped and sharp nose of KB203611 airfoil was subject to the leading edge stall. The leading edge stall is caused by separation of the laminar boundary layer at the nose that produces a bubble whose outer surface has a transition flow from laminar to turbulence.

At some AoAs, the bubble becomes unstable and bursts separating the flow over the entire top surface during the leading edge stall. The characteristics of leading edge stall are an abrupt change and a hysteresis in both lift and moment, and decreasing maximum lift with adding leading edge roughness (Prouty, 2002).

Figure 8. shows the contour of the local $\mathrm{x}$-directional velocity with a grip pitch of $12^{\circ}$ for the two airfoils. On the 
contours, the distributions of the pressure could be visualized as stiff on (a) KA152313 and gradual on (b) KB203611. There was no sign of turbulence in the contours because of the low pitch angle; however, signs of trailing stall appeared for the thick and blunt nosed airfoil of KA152313. Also, an abrupt lift change was expected from the drooped and sharp nosed airfoil in Figure 8(b).

As discussed, the types of stall affect the maximum lift and the effective range of the AoA. The stall type of the KA152313 airfoil would be a trailing edge stall occurring gradually; therefore, the separation started from the trailing edge at a relatively high AoA. However, the stall type of the KB203611 airfoil was the leading edge stall occurring suddenly; therefore, the separation expanded aft from the leading edge at a relatively low AoA.

\section{Force and moment distribution along the blade sections}

Figure 9 shows the coefficients of the normal pressure force and axial shear force along the blade span. The coefficients increased as the section radius decreased, but it could be decreased at the inner section due to the twist angle. The coefficient of the normal force $\left(C_{N}\right)$ increased as the GP increased and then decreased when stall occurred. However, the lift increased as the section radius increased (R1 is the largest radius) since the coefficient was based on the local flow velocity at each radius section. The coefficient of the axial shear force $\left(\mathrm{C}_{\mathrm{A}}\right)$ increased as the GP increased even though stall occurred. The coefficient of pressure should be maintained ideally near the maximum range for a proper design of the rotor.
The $\mathrm{C}_{\mathrm{N}}$ distribution of KA152313 airfoil was more useful than that of KB203611 at the inner sections (toward R12). In contrast, the $C_{N}$ of KB203611 airfoil at the outer section (toward tip) would increase rapidly as the GP increased. By integrating the lift through the blade span, the total lifts of a blade were estimated at the pitch angles, represented by the nominal GPs, shown in Figure 9.

Two of the most well known parameters used in aerodynamics are the $\operatorname{Re}\left(\rho V_{\infty} c / \mu\right)$ and Mach $\left(V_{\infty} / a\right)$, where the chord (c) is the characteristic length for an airfoil. The viscosity $(\mu)$, density $(\rho)$, and sonic velocity $(a)$ of fluid with a flow speed $\left(V_{\infty}\right)$ were used to define the parameters. The aerodynamic characteristics of the rotor airfoils must be assessed with their actual operational Re and Mach. For helicopters, the range of Re encountered by the rotor is significant and the Re effects on its aerodynamics are significant. The airfoils used for the agricultural helicopters were operated in the low ranges of $\mathrm{Re}$ $\left(0.2 \sim 1.0310^{6}\right)$ and Mach (0.1 0.4) along the blade span.

The physical significance of the Re is that it represents the ratio of the inertial forces to the viscous forces in the fluid. When viscous forces are dominant, the Re is small in value. At a low Re range for rotors (i.e., for chord Re in the range $10^{5}<\operatorname{Re}<10^{6}$ ), most airfoils have relatively low values of maximum $\mathrm{C}_{\mathrm{N}}$. This is because the viscous forces are more dominant, the boundary layer is thicker, and the flow will separate more readily from the airfoil surface (Wilby, 2001; Leishman, 2002).

When an airfoil travels at low speeds relative to the speed of sound, pressure disturbances travel at relatively high speeds in all directions. This causes the flow ap-

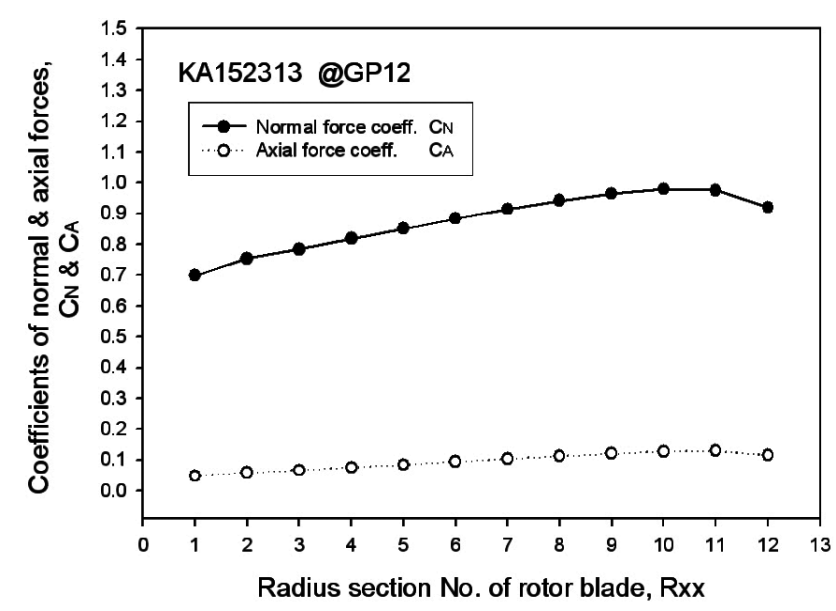

(a) KA152313

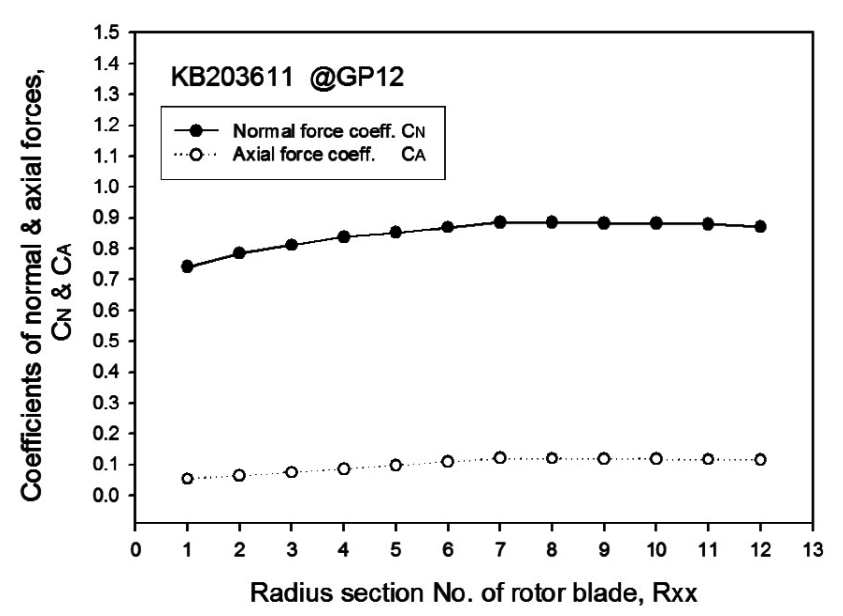

(b) KB203611

Figure 9. The coefficients of the normal and axial forces along the blade spans at a nominal grip pitch of $12^{\circ}$. 


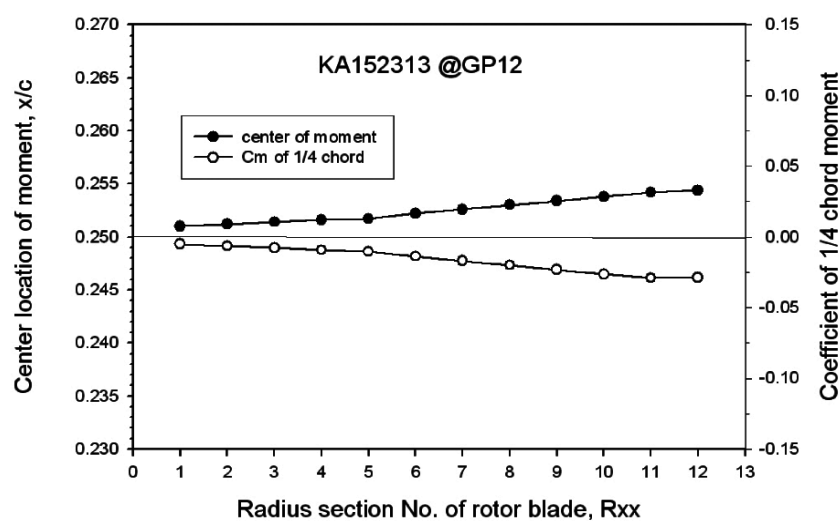

(a) KA152313

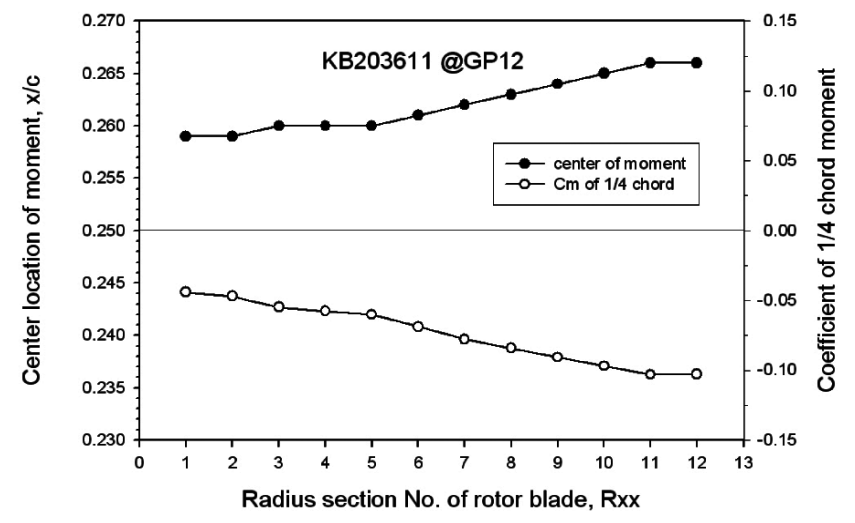

(b) KB203611

Figure 10. The coefficient of the pitching moment $\left(C_{m} 1 / 4\right)$ and its center location $\left(x_{c p}\right)$ on air foil $(x / c)$.

proaching the airfoil to change its velocity and pressure very gradually. The $\mathrm{C}_{\mathrm{N}}$ increases and then decreases after the maximum point with an increase of $\mathrm{Re}$, as the flow velocity increases. However, $\mathrm{C}_{\mathrm{A}}$ increases and then diverges with an increase of Mach. The Mach number, starting the divergence of the axial (drag) coefficient should be extended at the AoAs for a desired performance.

Figure 10 shows the coefficient of the pitching moment at the 1/4-chord position $\left(\mathrm{C}_{\mathrm{m} 1 / 4}\right)$ and the center location $\left(x_{c p}\right)$ of the moment on the airfoils along the blade span. The $C_{m} 1 / 4$ are normally negative, meaning nose (leading edge) up. The $\mathrm{C}_{\mathrm{m} 1 / 4}$ for a highly cambered foil of KB203611 was greater than that of KA152313 airfoil. The negative moments increased toward the inner section because of an increasing local AoA of the section.

Since the pitching moment is sensitive to small changes in the chord-wise pressure distribution, its variation with the AoA can be difficult to compute accurately. It was estimated by the integration of chord-wise pressure about some reference point. For a helicopter blade, the $1 / 4$-chord point is normally used. Converting from a reference point to $1 / 4$-chord point uses the rules of statics in Eqs. (4) and (5).

The effect of the airfoil shape on the pitching moment characteristics is of utmost concern for the design of helicopter rotors. Today, blades became torsionally stiffer because of their composite materials. This has allowed the better high lift capabilities of cambered airfoils to be utilized on modern helicopter blades (Leishman, 2002).

For the both blades, the center location moved aft from the relative chord $(\mathrm{x} / \mathrm{c})$ position of 0.25 , as the greater moment. For each value of the normal force, a single point can be determined about which the pitching moment is

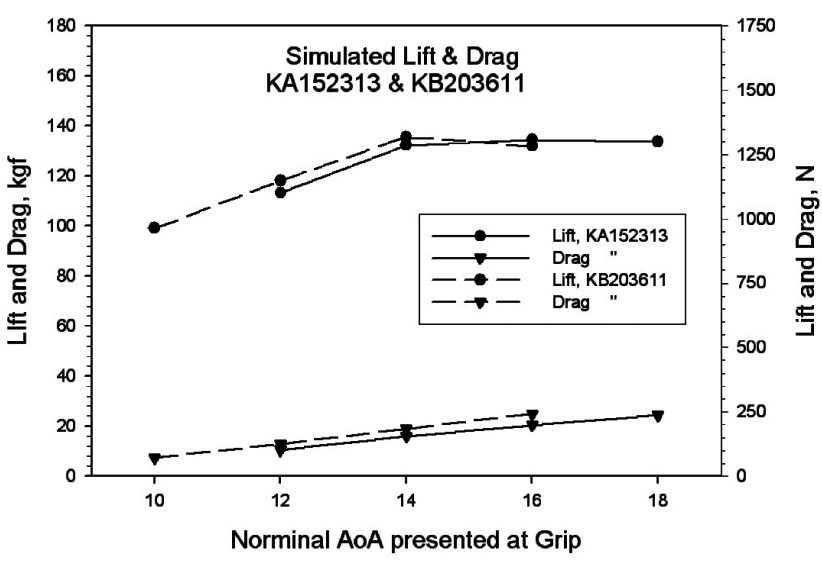

Figure 11. Comparison of the simulated lifts and drags for the two experimental blades.

zero. Therefore, the loading on the airfoil can be replaced only by normal and axial forces acting at this point, which is called the center of moment. The coefficient $C_{m} 1 / 4$ was generally negative, so that the center of moment was located behind the aerodynamic center (which is normally near 1/4-chord). Upon this effect, the center of moment moved forward and approached the aerodynamic center $(\mathrm{x} / \mathrm{c}=0.25)$ for higher values of $\mathrm{C}_{\mathrm{N}}$, but below stall.

Based on the analysis, it was found that the blades would perform properly at the inner sections of the KA152313 for high AoAs and better at the outer sections of the KB203611 for low AoAs.

\section{Comparison of the simulated and measured lifts}

Figure 11 compares the simulated lifts and drags of the two experimental blades. The simulated lift of the blade with KA152313 airfoil showed a smooth change for an 


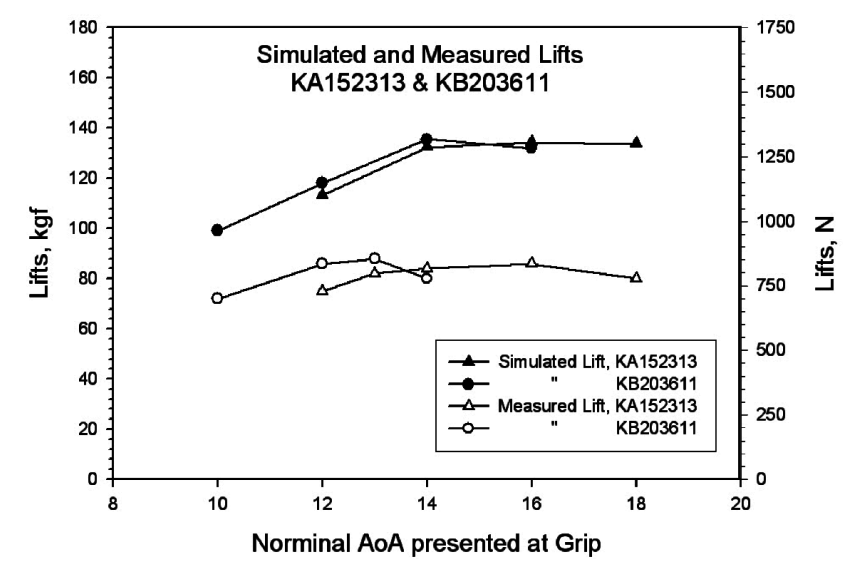

Figure 12. Comparison of the simulated and measured lifts for the two experimental blades.

increase of the AoA. The proper AoAs for the blade ranged between $14 \sim 18^{\circ}$. However, the simulated lift of KB203611 blade showed a maximum lift near 13 14 ${ }^{\circ}$.

The blade of KA152313 with greater thickness and blunt leading edge performed a smooth lift and gradual stall when the AoA increased. The trailing edge stall is gradual in both the lift and moment. The blade of KB203611 with the greater camber and drooped leading edge performed a narrow lift range and abrupt stall when the AoA increased. The characteristics of the leading edge stall are an abrupt change and hysteresis in both the lift and moment.

Generally, the drags increase with an increase of the AoA, and then would diverge at the higher AoAs. The drag of KB203611 blade was slightly higher than that of KA152313 at the same AoA.

Figure 12 compares the simulated and measured lifts for the two experimental blades. A discrepancy between the simulated and measured lifts was found because of a loss during the measurement and the limited power of the system. However, the general tendencies of the simulated and measured lifts agreed with each other.

In the actual measurement, a range of operable AoAs was GPs of $12 \sim 18^{\circ}$ for the blade of KA152313, while the AoA range for KB203611 blade was a GP of $12 \sim 14^{\circ}$. In this study, the lift performances of the two blades were different as follows: (1) the blade of KA152313 performed well over a wide range of AoAs and (2) the blade of KB203611 performed better at certain low AoAs.

Therefore, a variative blade was suggested, gradually emerging from grip to tip using KA152313 to KB203611 airfoils for an agricultural helicopter. The absolute local pitch angles along the blade span would be $12 \sim 10^{\circ}$ at the inner and $9 \sim 7^{\circ}$ at the outer section for a nominal GP angle of $12^{\circ}$ with a twist of $5^{\circ}$.

\section{Conclusions}

Aerial application using the agricultural helicopters helps in the precise and timely spraying of chemicals and reduces the required labor and environmental pollution. The utmost important element of an agricultural helicopter would be the rotor blade, lifting up the payload. In order to improve the performance of rotor blades, two types (KA152313 and KB203611) of airfoils and rotors were designed and compared using the CFD simulation method and experimental lift test.

The results for this study are summarized as follows:

(1) The nose shape of KB203611 airfoil was 'drooped' and 'sharp' compared to the leading edge of KA152313 airfoil. This drooped and sharp nose relaxed the shape of the distribution of pressure at the leading edge.

(2) The coefficient of the normal force $\left(\mathrm{C}_{N}\right)$ increased as the local pitch angle increased, and then decreased when stall occurred. The coefficient of the axial shear force $\left(C_{A}\right)$ increased even though stall occurred.

(3) The airfoils used for the agricultural helicopters were operated in the ranges of low $\operatorname{Re}\left(0.2 \sim 1.0310^{6}\right)$ and Mach (0.1 0.4) along the blade span. At a low Re range for the rotors most of the airfoils had relatively low values of $C_{N}$ because the viscous forces were more dominant.

(4) The coefficient of the 1/4-chord moment $\left(\mathrm{C}_{\mathrm{m}} 1 / 4\right)$ was normally negative, referring to nose up. The $\mathrm{C}_{\mathrm{m} 1 / 4}$ for a highly cambered foil of KB203611 was greater than that of KA152313 airfoil. For both blades, the center location moved aft from the relative chord position of 0.25 for greater moments.

(5) The simulation results showed that the proper range of AoAs for the KA152313 blade was 14 18 ${ }^{\circ}$; however, the simulated lift of KB203611 blade showed a maximum lift near $13 \sim 14^{\circ}$. The drags increased with an increase of AoA.

(6) In the actual measurements, the ranges of operable AoAs were the GPs of $12 \sim 18^{\circ}$ and $12 \sim 14^{\circ}$ for the blades of KA152313 and KB203611, respectively.

In this study, the lift performances of the two blades 
were different as follows: (1) the blade of KA152313 performed well over a wide range of AoAs and (2) the blade of KB203611 performed better at low AoAs. Therefore, to improve the performance of rotor blade for an agricultural helicopter a blade gradually emerging from grip to tip with the two different airfoils was suggested. The proper local pitch angles along the blade span would be $12 \sim 10^{\circ}$ at the inner and $9 \sim 7^{\circ}$ at the outer section, at a nominal GP of $12^{\circ}$ with a twist angle of $5^{\circ}$

\section{Conflict of Interest}

No potential conflict of interest relevant to this article was reported.

\section{Acknowledgments}

This research was supported by a fund of the Kyungpook National University Research Fund, 2009

\section{References}

Kim, S.J. 2005. Airfoil aerodynamic analysis for the helicopter rotor blade preliminary design. Journal of Aeronautical and Space Sciences 33(6):21-30 (In Korean).

Koo, Y. M. 2009. Development of essential mechanical elements for unmanned agricultural helicopter with payload of $20 \mathrm{~kg}$. Final Report for IUPL of SMBA, MOCIE. Daegu, Korea (In Korean).

Koo, Y. M., C. S. Lee, T. S. Soek, S. K. Shin, T. G. Kang, S. H. Kim and T. Y. Choi. 2006a. Aerial application using a small RF controlled helicopter (I) -status and cost analysis-. Journal of Biosystems Engineering 31(2):
95-101 (In Korean).

Koo, Y. M., T. S. Soek, S. K. Shin, C. S. Lee and T. G. Kang. 2006b. Aerial application using a small RF controlled helicopter (III) -lift test and rotor system-. Journal of Biosystems Engineering 31(3):182-187 (In Korean).

Koo, Y. M., T. S. Seok and S. K. Shin. 2010. SW05 rotor lift of an unmanned helicopter for precise ULV aerial application. Journal of Biosystems Engineering 35(1):31-36 (In Korean).

Leishman, J.G. 2002. Principles of Helicopter Aerodynamics. New York: Cambridge University.

Park, Y. M., B. H. Chang, K. H. Chung and C. J. Hwang. 2004. Low Reynolds airfoil design for unmanned helicopter rotor blade. Proceedings of Fall Conference in the Korean Society for Aeronautical and Space Science, pp. 798-801 (In Korean).

Prouty, R. W. 2002. Helicopter performance, stability, and control. Malabar, FL: Krieger Pub. Co. Inc.

Sa, J. H., S. M. Lee, S. H. Park, C. J. Kim, Y. H. Yoo, K. H. Jung, and S. B. Kim. 2010. Effect of blade planform and airfoil configurations on hovering performance of rotor blades. Proceedings of Fall Conference in the Korean Society for Aeronautical and Space Science, pp. 976-979 (In Korean).

Soek, T. S., Y. M. Koo, C. S. Lee, S. K. Shin, T. G. Kang and S.H. Kim. 2006a. Aerial application using a small RF controlled helicopter (II) -development of power unit-. Journal of Biosystems Engineering 31(2):102-107 (In Korean).

Seok, T. S., Y. M. Koo and C. H. Sohn. 2006b. Aerial application using a small RF controlled helicopter (IV CFD simulation of rotor lift-. Journal of Biosystems Engineering 31(4):343-348 (In Korean).

Wilby, P.G. 2001. The development of rotor airfoil testing in the UK. Journal of the American Helicopter Society 46(3):210-220. 